Journal of Thermal Engineering, Vol. 6, No. 3, pp. 214-226, April, 2020

Yildiz Technical University Press, Istanbul, Turkey

\title{
MATHEMATICAL MODELLING OF LOW GRADE THERMAL ENERGY STORAGE USING AN ENCAPSULATED LIQUID MEDIUM
}

\author{
Law Torres Sevilla ${ }^{1}$, Jovana Radulovic ${ }^{1, *}$
}

\begin{abstract}
In the present study, we report the results obtained from numerical simulations of low grade heat storage. Four different fluid encapsulated materials were tested in four design types for their suitability as a small scale, low temperature thermal energy storage (TES). This was done by analysing and evaluating the maximum temperature reached per sphere for three different positions inside the tank, which correspond to the top right, centre and bottom right sphere. The influences of the material properties and the inlet/outlet tank designs were analysed and evaluated based on the results. The heat transfer fluid (HTF) was water and the storage materials selected were water, glycerol, MDM and MD3M. These were heated sensibly from an ambient temperature of $20^{\circ} \mathrm{C}$ to $90^{\circ} \mathrm{C}$. The analysis shows that the materials with the highest relevant properties do not in fact charge the tank the fastest. Furthermore, the design of the inlet greatly affects the heating dynamics of the system, whereas changing the outlet design marginally affects the results.
\end{abstract}

Keywords: Thermal Energy Storage, COMSOL Multiphysics, Storage Material, Sensible Heat

\section{INTRODUCTION}

The world is embarking into a fossil fuel free environment in which the predominant sources will be renewable and sustainable energies. Since renewable energy is usually associated with their intermittent nature, it is important to always have a backup source of energy in times of need and demand. Thus, Thermal Energy Storage (TES) is one of the proposed solutions to aid in this mismatch in consumption and demand caused by the nature of the green technologies.

In low grade energy, when the temperatures are not high enough to induce a phase change, only sensible heat storage is considered. The research proposes a single-tank packed bed, which compared to a two-tank system with a thermocline can reduce the cost by approximately $35 \%$ [1]. With a thermocline, however, the efficiency of the system is compromised, as stated by Ling et al., where in a tank with a $32 \mathrm{~m}$ height and a $5 \mathrm{~m}$ radius, the thermocline can be 4 $5 \mathrm{~m}$ [2]. As opposed to a thermocline, a single tank with a full charged-discharged cycle, where the totality of the tank is used as hot storage, is proposed.

Research on packed beds has been carried out extensively for over two decades now. Solid materials such as pebbles, rocks, concrete, ceramics etc. [3, 4] are commonly used in packed beds, which offers a number of advantages, including low cost and heat losses, non-toxic and non-flammable nature of these materials [5]. White et al. investigated a packed bed arrangement with various storage materials and Argon as Heat Transfer Fluid (HTF) for pumped thermal storage [6]. They concluded that magnetite is a suitable choice due to its properties: high heat capacity per unit volume and low fractional variation of heat capacity over temperature ranges [7]. Similarly, N. Mertens et al. assessed the suitability of a quartzite rock randomly packed bed with air as the HTF to work in conjunction with a semi-industrial scale solar power plant. Their results indicate economical and cost saving advantages, however with reduced the plant efficiency [8]. R. Lugolole et al. suggests granite pebbles as the filler for an experimental packed bed setup in which the HTF is sunflower oil. Their results are in agreement with previous studies confirming good thermal performance due to high specific heat capacity and low viscosity at high temperatures, which is beneficial for the ease of circulation [9]. Furthermore, Mawire A. published experimental results of the performance of sunflower oil as both a heat storage

This paper was recommended for publication in revised form by Regional Editor Hafiz Muhammad Ali

${ }^{1}$ School of Mechanical and Design Engineering, University of Portsmouth, Portsmouth, United Kingdom

${ }^{*}$ E-mail address: jovana.radulovic@port.ac.uk

Orcid id: 0000-0002-3424-4383, 0000-0002-9378-7214

Manuscript Received 7 June 2019, Accepted 24 September 2019 
medium and heat transfer fluid, reporting that high temperature charging resulted in high energy and exergy, but faster heat loss and low heat retention [10].

Other solutions include the use of phase-changing materials in solid packed beds as hybrid system. This approach addresses the disadvantages of latent heat systems, such as low thermal conductivity and poor heat transfer rates, and the advantages of sensible heat systems, such as low storage capacity. In order to be used in a packed bed, PCMs are encapsulated to help with leaking issues and improve conduction and heat transfer. Ahmed et al. investigated the effect of porosity, inlet velocity, feature size of the rods, discharge efficiency and discharge time on the performance of a single tank with solid brick manganese rod structures, vertically positioned, with gaps between the rod filled by D-Mannitol PCM capsules. Results indicated that discharge efficiency can be increased by using a lower inlet velocity, by decreasing porosity of the PCM or by reducing the rod feature size [11]. Ismail et al. investigated the effect of the working fluid entry temperature and the mass flow as well as the temperature of water and ethylene glycol (30\%) filled capsules that phase change from liquid to gas [12]. They concluded that the entry temperature of the working fluid had a dominant and strong effect on phase change behaviour. Wu et al. numerically modelled packed bed with encapsulated paraffin wax reporting longer phase change period for larger inlet velocities, despite enhanced heat transfer coefficient [1].

Liquids typically have higher specific heat capacity than gases, hence higher heat absorption and better thermal performance in sensible heat applications. Mawire et al. suggested the use of thermal oil in a domestic single tank thermal storage over water due to its boiling temperature limitation. They also noted that using a full tank solely filled of thermal oil as a heat storage material would be expensive, so combination of the oil with a pebble based packed bed is proposed, which was found to also improve stratification on the system, its efficiency and reduce thermal degradation [13].

Current literature focuses on the use of solid materials on sensible heat storage and liquid materials are analysed for latent heat absorption. Little is known about liquid materials suitability for sensible heat applications. This paper aims to assess the suitability of packed spheres filled with liquid materials for sensible heat storage. We also present a mathematical model to quantitative describe dynamics of charging.

\section{METHODOLOGY}

The system analysed consists of a cylindrical tank with shelled spheres packed bed, containing the selected storage materials and water as the HTF. The main parameters are listed in Table 1.

Table 1. Parameters for the TES simulations

\begin{tabular}{|l|l|}
\hline Parameters & Values \\
\hline Initial temperature of system $\left(\mathrm{T}_{\text {sys }}\right):$ & $20^{\circ} \mathrm{C}$ \\
\hline Inlet temperature of $\mathrm{HTF}\left(\mathrm{T}_{\text {in }}\right):$ & $90^{\circ} \mathrm{C}$ \\
\hline Inlet velocity $\left(\mathrm{u}_{\text {in }}\right):$ & $0.1 \mathrm{~m} / \mathrm{s}$ \\
\hline Tank radius & $0.25 \mathrm{~m}$ \\
\hline Tank height & $0.5 \mathrm{~m}$ \\
\hline Tank thickness: & $0.025 \mathrm{~m}$ \\
\hline Sphere outer radius: & $0.030 \mathrm{~m}$ \\
\hline Sphere inner radius: & $0.025 \mathrm{~m}$ \\
\hline
\end{tabular}

Four materials were considered as storage media: water $\left(\mathrm{H}_{2} \mathrm{O}\right)$, glycerol $\left(\mathrm{C}_{3} \mathrm{H}_{8} \mathrm{O}_{3}\right)$, MDM $\left(\mathrm{C}_{8} \mathrm{H}_{24} \mathrm{O}_{2} \mathrm{Si}_{3}\right)$ and $\mathrm{MD} 3 \mathrm{M}\left(\mathrm{C}_{12} \mathrm{H}_{36} \mathrm{O}_{4} \mathrm{Si}_{5}\right)$. Thermal storage characteristics of these materials were evaluated for four different tank designs shown in Figure 1. All tank designs were symmetrical along the y-axis. 
- Design 1: centrally placed inlet (width $0.12 \mathrm{~m}$ ) and outlet equal to the tank diameter $0.5 \mathrm{~m}$

- Design 2: centrally placed inlet and outlet (width $0.12 \mathrm{~m}$ )

- Design 3: centrally placed inlet (width $0.12 \mathrm{~m}$ ) on the top of trapezoidal dome (height $0.1 \mathrm{~m}$, approximately $21^{\circ}$ angle) and outlet equal to the tank diameter $0.5 \mathrm{~m}$

- Design 4: centrally placed inlet and outlet (width $0.12 \mathrm{~m}$ ) at the top and bottom of the trapezoidal domes

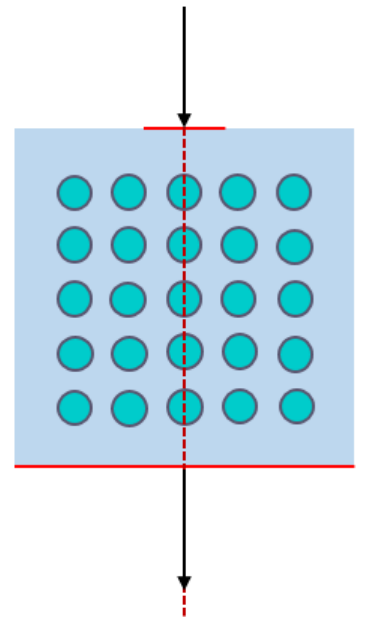

(1)

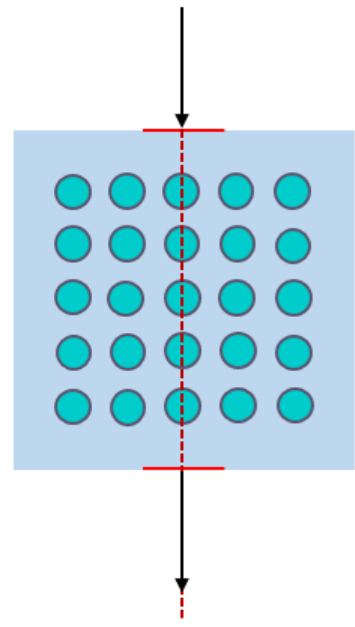

(2)

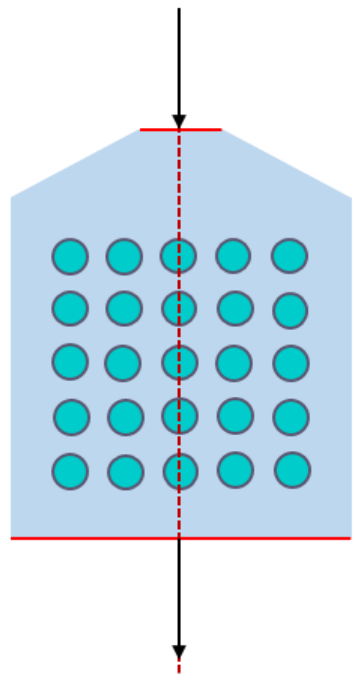

(3)

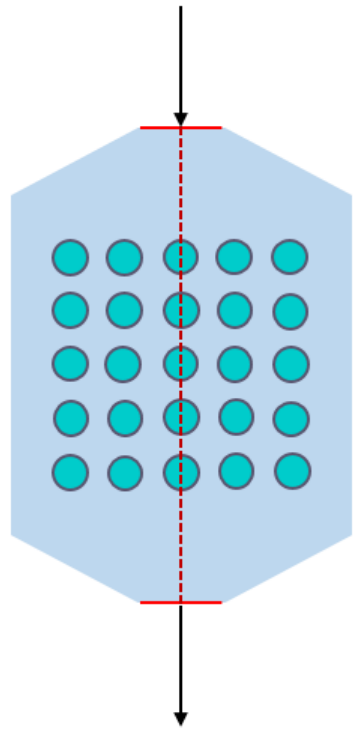

(4)

Figure 1. Four tank designs

The heating dynamics of the system and temperature change was monitored at three different positions inside the tank, as shown in Figure 2: the centre sphere, and two spheres at the top and bottom corners of the tank. By observing these selected positions, thermal profile across the tank can be easily captured and succinctly presented whilst capturing the charging dynamics [12]. The final temperatures reached and heating dynamics were evaluated for all materials and all designs. Results were analysed to determine the effect of the tank inlet/outlet design, the influence of the material properties and to quantify the dynamics of the heat transfer process.

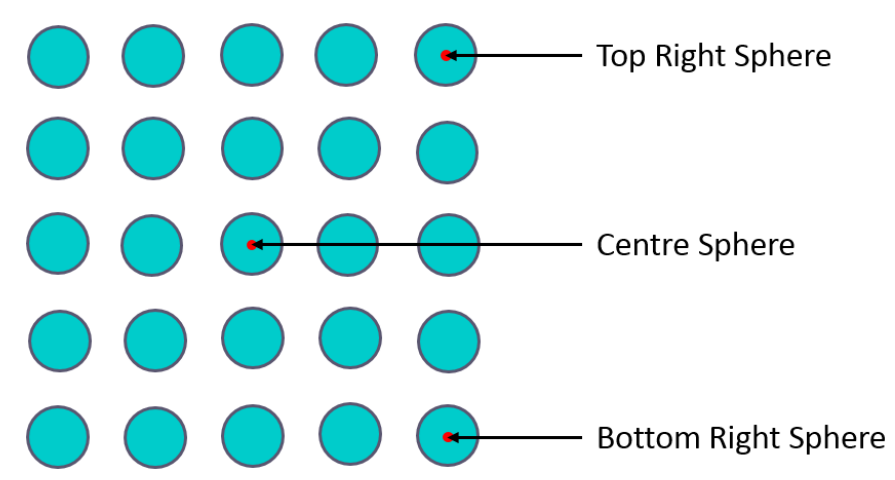

Figure 2. Three different positions for heating dynamics analysis

The HTF selected was water, due to its desirable fluid transport properties. The tank frame is modelled as aluminium and the void capsules in which the storage material is secluded are annealed stainless steel 405 . The relevant properties for the tested storage materials can be found in Table 2: 
Journal of Thermal Engineering, Research Article, Vol. 6, No. 3, pp. 214-226, April, 2020

Table 2. Relevant properties of the tested materials taken at a reference temperature of $55^{\circ} \mathrm{C}[14,15]$

\begin{tabular}{|c|c|c|c|c|c|c|}
\hline Material & $\begin{array}{c}\text { Specific Heat } \\
\text { Capacity } \\
(\mathrm{J} / \mathbf{k g} \cdot \mathbf{K}) \\
\end{array}$ & $\begin{array}{l}\text { Density } \\
\left(\mathbf{k g} / \mathrm{m}^{3}\right)\end{array}$ & $\begin{array}{c}\text { Dynamic } \\
\text { Viscosity } \\
(\mu \mathrm{Pa} \cdot \mathrm{s}) \\
\end{array}$ & $\begin{array}{c}\text { Kinematic } \\
\text { Viscosity } \\
(\mu \mathrm{Pa} \cdot \mathrm{s}) \\
\end{array}$ & $\begin{array}{c}\text { Thermal } \\
\text { Conductivity } \\
\left(\mathrm{cm}^{2} / \mathrm{s}\right)\end{array}$ & $\begin{array}{c}\text { Thermal } \\
\text { Diffusivity } \\
\left(\mathrm{m}^{2} / \mathbf{s}\right)\end{array}$ \\
\hline Water & 4.1830 & 985.69 & 503.62 & 0.005109 & 646.02 & 0.00156680 \\
\hline Glycerol & 2.4262 & 1239.70 & 108740.00 & 0.877400 & 284.70 & 0.09465515 \\
\hline MDM & 1.8721 & 785.36 & 575.73 & 0.007331 & 93.66 & 0.00063704 \\
\hline MD3M & 1.7633 & 841.24 & 1178.50 & 0.014010 & 107.65 & 0.00072575 \\
\hline
\end{tabular}

Assumptions include the following:

(i) No heat transfers or losses related to radiation.

(ii) The outside of the tank is perfectly insulated.

(iii) The HTF (water) is laminar and incompressible.

(iv) The properties of the materials are homogeneous and isotropic.

(v) The spheres are perfectly circular and do not deform.

The system is an open flow system, modelled in 2D using the software COMSOL Multiphysics. The physics models 'heat transfer in fluids' and 'laminar flow' were used. Validation of the physics model was carried out based on the system reported [16]. The mesh is a fine, free triangular mesh with the triangle size being smaller for the spheres than the rest of the tank [17]. An example of the mesh for the design (2) is shown in Figure 3. The boundary layers considered are a velocity boundary at the inlet and a pressure boundary layer at the outlet. The walls are no slip condition and the fluid is weakly compressible. The system is symmetrical across the y-axis [18].

The simulation is set to run for $40 \mathrm{~h}$ in intervals of $0.1 \mathrm{~h}$. Initially, the whole system is at the initial temperature of $T_{\text {sys. }}$ At time 0 , water at $T_{\text {in }}$ and $u_{\text {in }}$ starts flowing from the inlet, across the tank, to the outlet, heating up the encapsulated material throughout the selected timeframe.

The heat transfer process for a single sphere can be mathematically expressed as:

$$
\frac{d T}{d t}=\frac{\left(T_{\infty}-T\right)}{\tau}
$$

with the exact solution expressed as:

$$
T=T_{\infty}-\left(T_{\infty}-T_{i}\right) \cdot \exp \left(\frac{-t}{\tau}\right)
$$

where $T_{i}$ is the initial temperature of the sphere, $T_{\infty}$ is heat transfer fluid temperature and $\tau$ is thermal time constant, defined as:

$$
\tau=\frac{\rho V c}{h A}
$$

where $\rho$ is density, $c$ is specific heat capacity, $h$ is the heat transfer coefficient, and $A$ and $V$ are the contact area and volume of the sphere. For the given system, as the first approximation, the convection coefficient can be calculated using Whitaker's correlation for a sphere [19]

$$
N u=\frac{d h}{k}=2+\left[0.4 \operatorname{Re}_{\infty}^{1 / 2}+0.06 \operatorname{Re}_{\infty}^{2 / 3}\right] \operatorname{Pr}^{0.4}\left(\frac{\mu_{\infty}}{\mu_{s}}\right)^{1 / 4}
$$

valid for $3.5 \leq R e_{\infty} \leq 7.6 \cdot 10^{4}, 0.71 \leq P r_{\infty} \leq 380$ and $0.1 \leq\left(\frac{\mu_{\infty}}{\mu_{s}}\right) \leq 3.2$ Reynolds, Prandtl and Nusselt numbers calculated at $T_{\infty}$. The single sphere correlation has been successfully applied to packed bed arrangements [20]. 


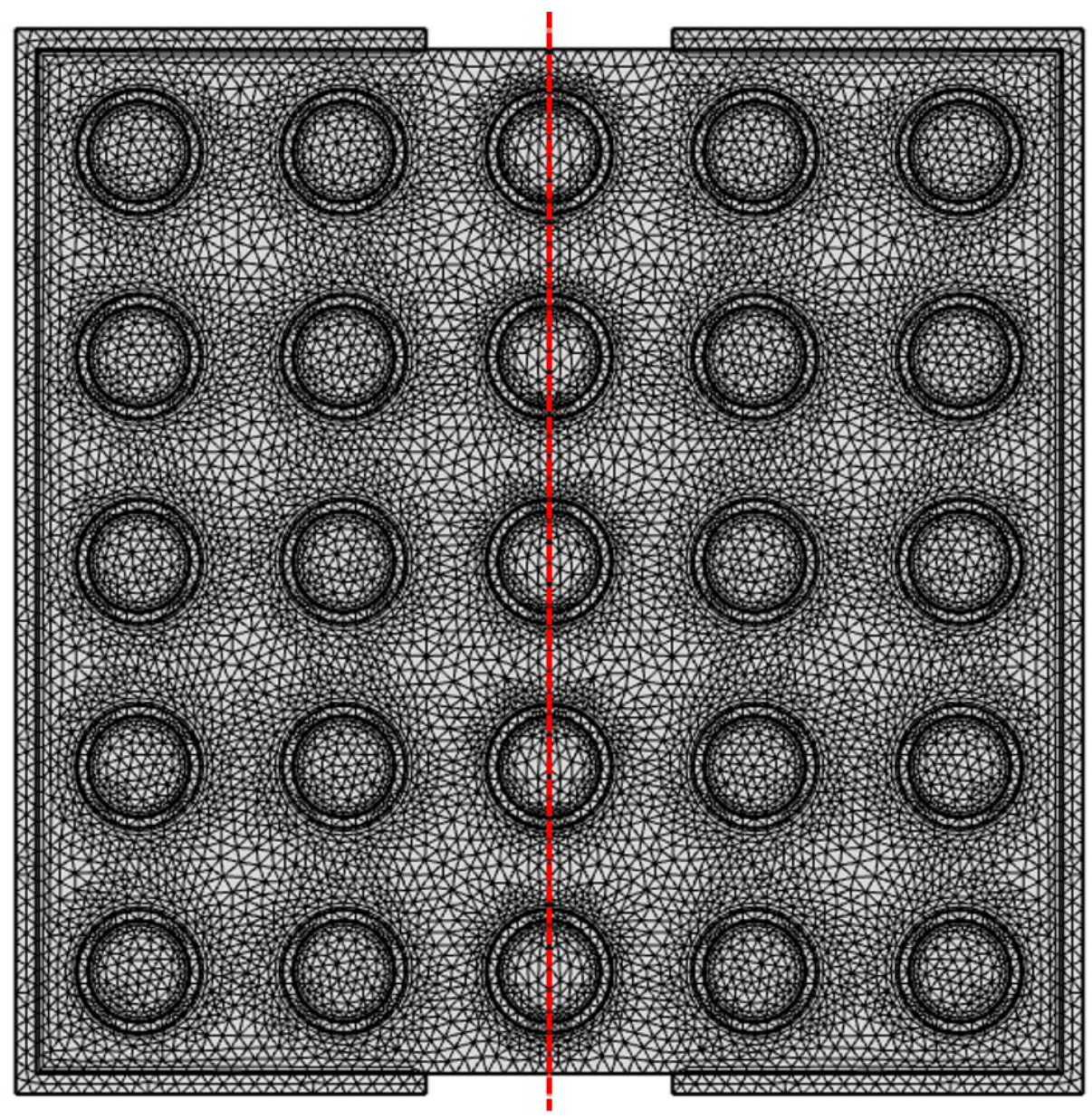

Figure 3. System mesh for design (2) in COMSOL Multiphysics

\section{RESULTS AND DISCUSSION}

As the heat transfer fluid is introduced into the packed bed, it spreads across the tank and the heat transfer commences. Spheres absorb heat at different rates depending on the position and the storage material. The spheres closest to the inlet benefit the most from this heat exchange. The bottom sphere follows the top one, and has a significantly steep gradient. However, the centre sphere experiences a harsh initial lag, probably due to the HTF flowing quickly, straight from inlet to outlet, and not allowing enough contact time for the heat transfer to occur.

The differences from having an open outlet to a closed one in designs (1) and (2) are negligible for top and bottom positions. This suggests that the inlet is the key element in the design and that the outlet makes little or no impact on the heating of the storage material. This idea is further supported in Figure 6 from the differences between designs (3) and (4), where the extra dome added into the outlet barely affects the final temperatures for both positions. From this data it can be determined that the difference in temperatures from the top of the tank to the bottom is approximately $3 \%$ for each material. 
Journal of Thermal Engineering, Research Article, Vol. 6, No. 3, pp. 214-226, April, 2020
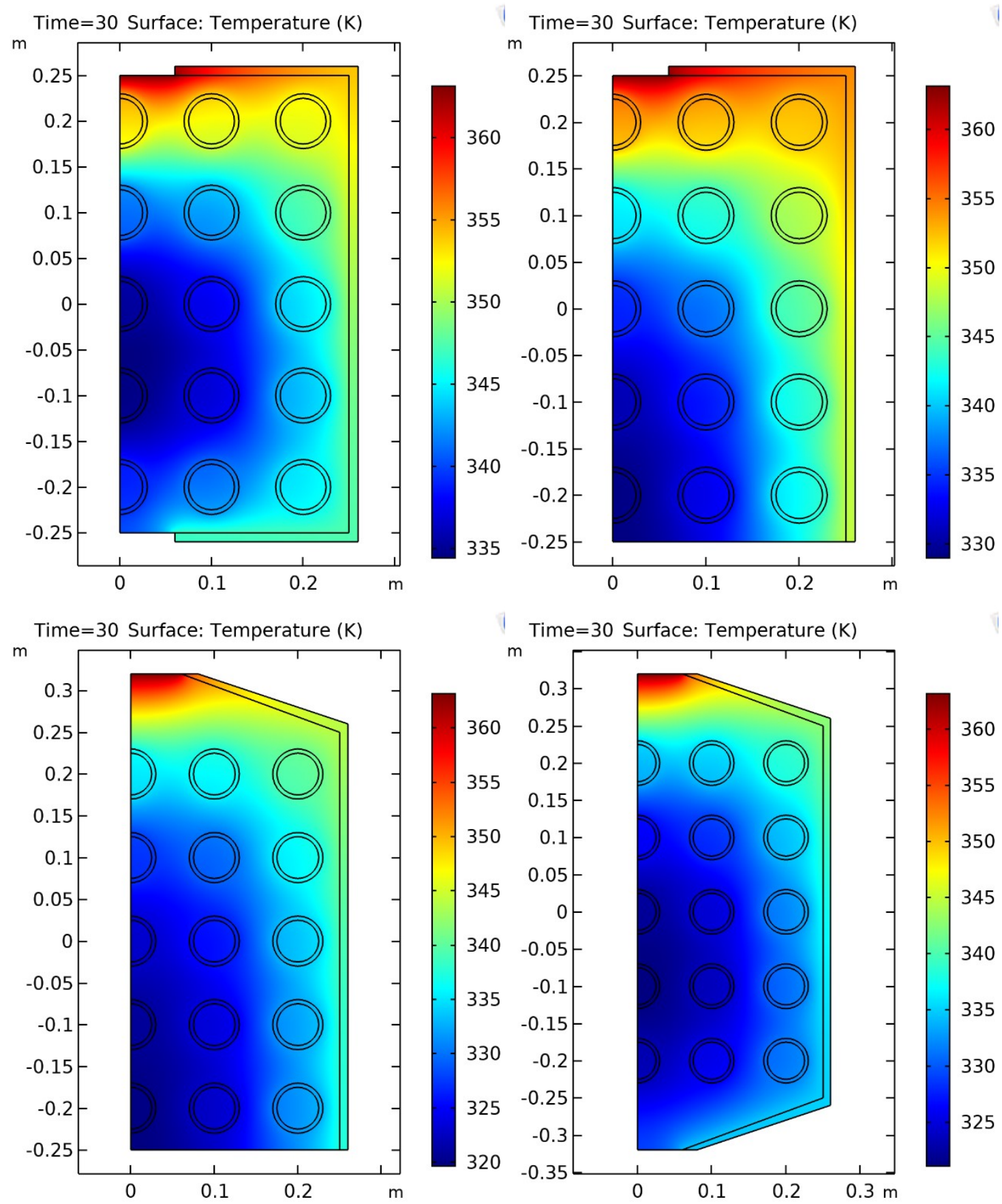

Figure 4. Temperature distribution at $\mathrm{t}=30 \mathrm{~s}$ for four considered tank designs (results presented for water) 
Journal of Thermal Engineering, Research Article, Vol. 6, No. 3, pp. 214-226, April, 2020

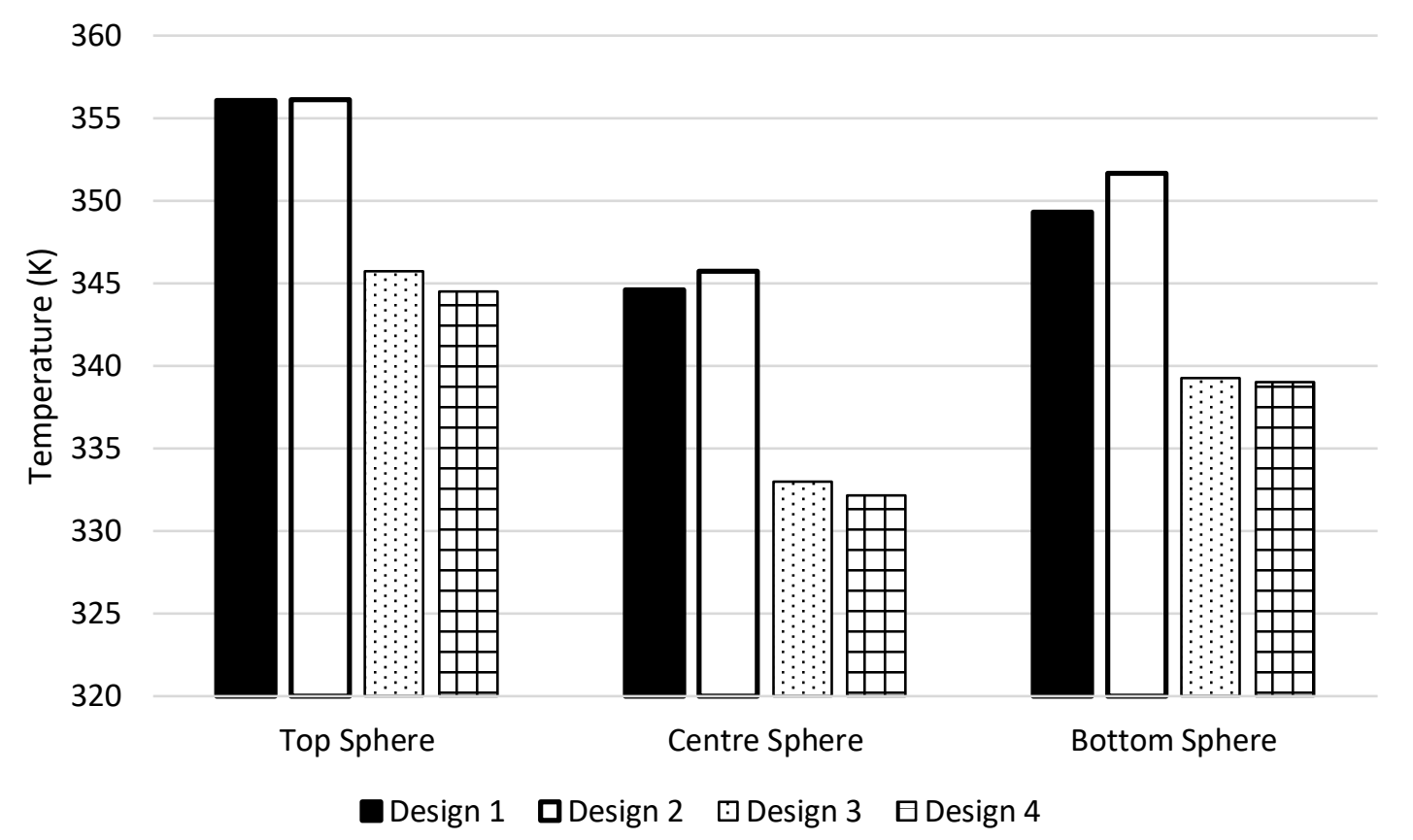

Figure 5. Final temperatures for the selected positions for four considered tank designs (results presented for water)

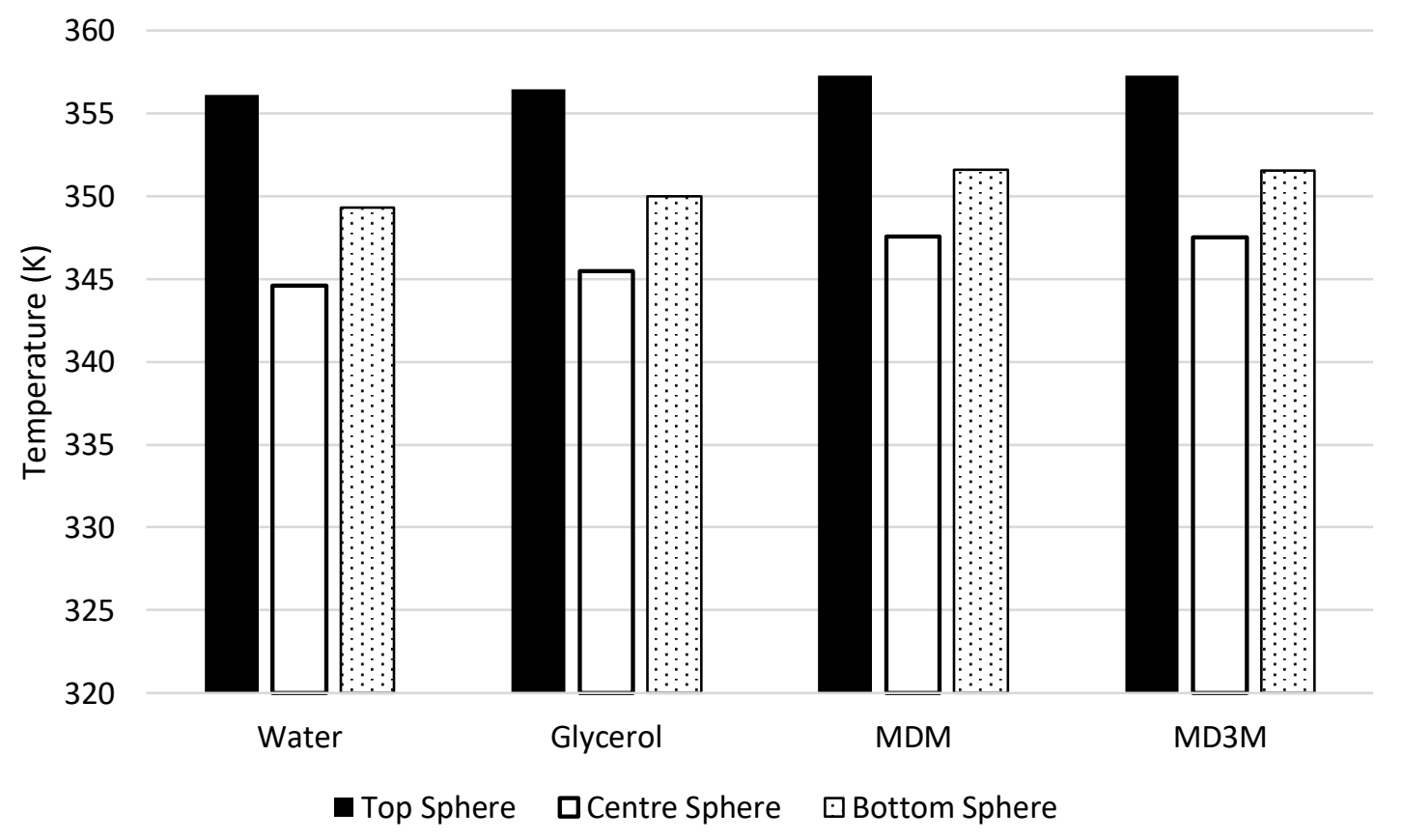

Figure 6. Final temperatures for the selected positions for the four considered materials for design (1) 
Additionally, the maximum difference in final temperature across designs and materials was also $\sim 3 \%$, even though their properties are significantly different. This data can be found in Table 3, where the percentage differences between the temperatures for all tank designs for the top and bottom spheres were calculated:

Table 3. Percentage difference between Tf for all materials, for all designs, for two positions

\begin{tabular}{|c|c|c|c|c|c|c|}
\hline & \multicolumn{6}{|c|}{ Percentage Difference (Top Spheres) } \\
\hline Material & $\begin{array}{l}\text { (1) } \mathrm{Tf}- \\
\text { (2) } \mathrm{Tf}\end{array}$ & $\begin{array}{c}\text { (1) } \mathrm{Tf}- \\
\text { (3) } \mathrm{Tf}\end{array}$ & $\begin{array}{l}\text { (1) } \mathrm{Tf}- \\
\text { (4) } \mathrm{Tf}\end{array}$ & $\begin{array}{c}\text { (2) } \mathrm{Tf}- \\
\text { (3) } \mathrm{Tf}\end{array}$ & $\begin{array}{c}\text { (2) } \mathrm{Tf}- \\
\text { (4) } \mathrm{Tf}\end{array}$ & $\begin{array}{c}\text { (3) } \mathrm{Tf}- \\
\text { (4) } \mathrm{Tf}\end{array}$ \\
\hline Water & $0.00 \%$ & $2.91 \%$ & $3.26 \%$ & $2.92 \%$ & $3.26 \%$ & $0.35 \%$ \\
\hline Glycerol & $0.03 \%$ & $2.81 \%$ & $3.18 \%$ & $2.84 \%$ & $3.21 \%$ & $0.38 \%$ \\
\hline MDM & $0.01 \%$ & $2.67 \%$ & $3.01 \%$ & $2.66 \%$ & $2.99 \%$ & $0.34 \%$ \\
\hline \multirow[t]{2}{*}{ MD3M } & $0.05 \%$ & $2.64 \%$ & $2.99 \%$ & $2.69 \%$ & $3.04 \%$ & $0.36 \%$ \\
\hline & \multicolumn{6}{|c|}{ Percentage Difference (Bottom Spheres) } \\
\hline Material & $\begin{array}{l}\text { (1) } \mathrm{Tf}- \\
\text { (2) } \mathrm{Tf}\end{array}$ & $\begin{array}{c}\text { (1) } \mathrm{Tf}- \\
\text { (3) } \mathrm{Tf}\end{array}$ & $\begin{array}{c}\text { (1) } \mathrm{Tf}- \\
\text { (4) } \mathrm{Tf}\end{array}$ & $\begin{array}{c}\text { (2) } \mathrm{Tf}- \\
\text { (3) } \mathrm{Tf}\end{array}$ & $\begin{array}{c}\text { (2) } \mathrm{Tf}- \\
\text { (4) } \mathrm{Tf}\end{array}$ & $\begin{array}{l}\text { (3) } \mathrm{Tf}- \\
\text { (4) } \mathrm{Tf}\end{array}$ \\
\hline Water & $0.67 \%$ & $2.88 \%$ & $2.94 \%$ & $2.92 \%$ & $3.26 \%$ & $0.35 \%$ \\
\hline Glycerol & $0.69 \%$ & $2.79 \%$ & $2.90 \%$ & $2.84 \%$ & $3.21 \%$ & $0.38 \%$ \\
\hline MDM & $0.55 \%$ & $2.72 \%$ & $2.83 \%$ & $2.66 \%$ & $2.99 \%$ & $0.34 \%$ \\
\hline MD3M & $0.65 \%$ & $2.67 \%$ & $2.80 \%$ & $2.69 \%$ & $3.04 \%$ & $0.36 \%$ \\
\hline
\end{tabular}

Temperatures of the top sphere for designs 1 and 2 are very similar. A larger tank outlet had positive effect on heat absorption as the central and bottom spheres reached somewhat higher temperature values. The effect of the inlet dome can be assessed by comparing designs 1 and 3 . In all cases $\sim 10^{\circ} \mathrm{C}$ lower temperatures have been seen for design 3. The effect is additionally emphasised for the middle sphere. Mixing in the dome area allows for developed flow across the tank. The residence time of the heat transfer fluid is reduced; hence, a lower temperature increase. A comparison of design 3 and 4, shows further decrease in heat gain when a bottom dome is employed. Results indicate that restricted inlet size, and to a lesser extent outlet, govern the fluid residence time in the tank as shown in temperature profiles in Figure 4. The central position of both inlet and outlet in design 1 causes a "downstream" flow through the middle of the tank, resulting in lower heat absorption by the middle sphere. Top and bottom spheres at the "corners" of the tank benefit from laminar flow regime and the heat gain is higher. Comparable trends have been reported in [12]. Naturally, as the heat is transferred across the tank, the temperature of the heat transfer fluid decreases and heat transfer is lessened in spheres at the bottom of the tank.

Temperatures vs time graphs were plotted in the software ORIGIN. The heating dynamics for each position inside the tank are different, but each material follows the same trend. An example of these graphs can be found in Figure 7, where design (2) results are shown for water as the storage material: 


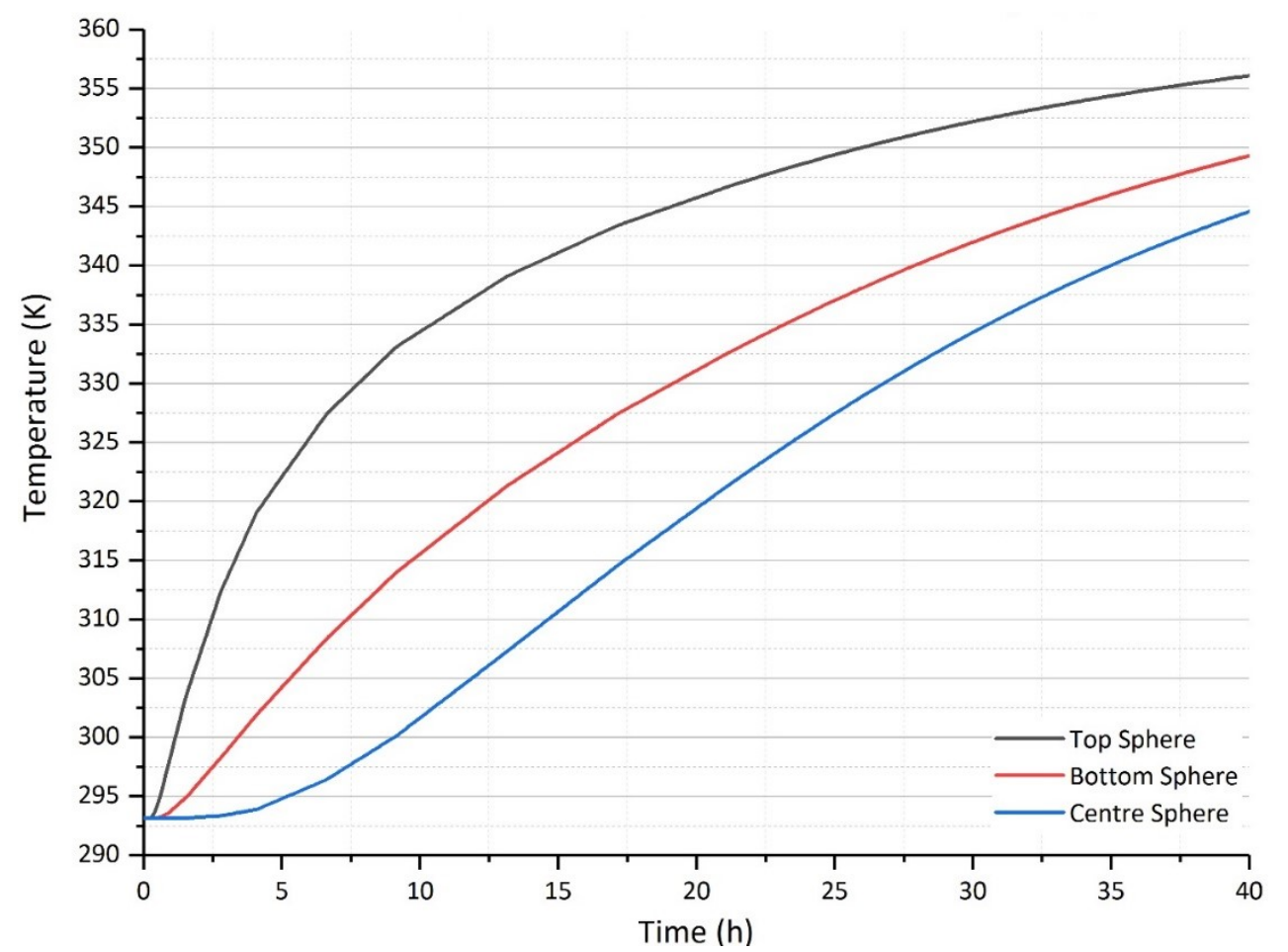

Figure 7. Temperature vs Time graph of water as storage material, for design (2), all positions

The highest temperature is always reached by MDM for all positions. This is followed by MD3M, Glycerol and lastly Water. While MDM has rather low average specific heat capacity, it also features the lowest density of the selected materials. A naïve analysis indicates that materials with low volumetric heat capacity $(\rho \cdot c)$ absorb heat faster.

Although the final temperatures for all materials are different, they all follow the same heating dynamics. The general shapes of the lines in each of the three graphs are the same. This reflects on the possibility that the properties, although they can affect the final temperature reached, do not in fact affect the dynamics. Using ORIGIN's fitting tool, exponential growth fits were added to each individual temperature vs time plot. The fittings were applied only to the top and bottom positions of the tank, excluding the centre sphere. The equation utilised by the software is Equation 5 .

$$
y=y_{o}-A_{1} \cdot \exp \left(\frac{-x}{t_{1}}\right)
$$

where $y$ is the temperature, $y_{0}$ is the final temperature approached, $A_{I}$ is the amplitude, $x$ is the rate of growth and $t_{l}$ is the time. It is important to note that Equations 2 and 5 are comparable and their coefficients can be related. For instance, $y_{0}$ in Equation 2 correlates to the final temperature $\mathrm{T}$ in Equation 5. Equally, the $t_{l}$ time constant can be compared to the calculated $\tau$ coefficient.

Two graphs for all materials, for the top sphere position and design (2) are shown below as an example in Figures 8 and 9. Figure 8 expresses the temperatures acquired by the numerical simulation and Figure 9 displays the fits produced in ORIGIN. The final parameters for each material, for all designs and two positions (top/bottom) were recorded. An example for Water is shown below in Table 4. Furthermore, the results for all materials for one design type for top and bottom positions was also added in Table 5 . 
Journal of Thermal Engineering, Research Article, Vol. 6, No. 3, pp. 214-226, April, 2020

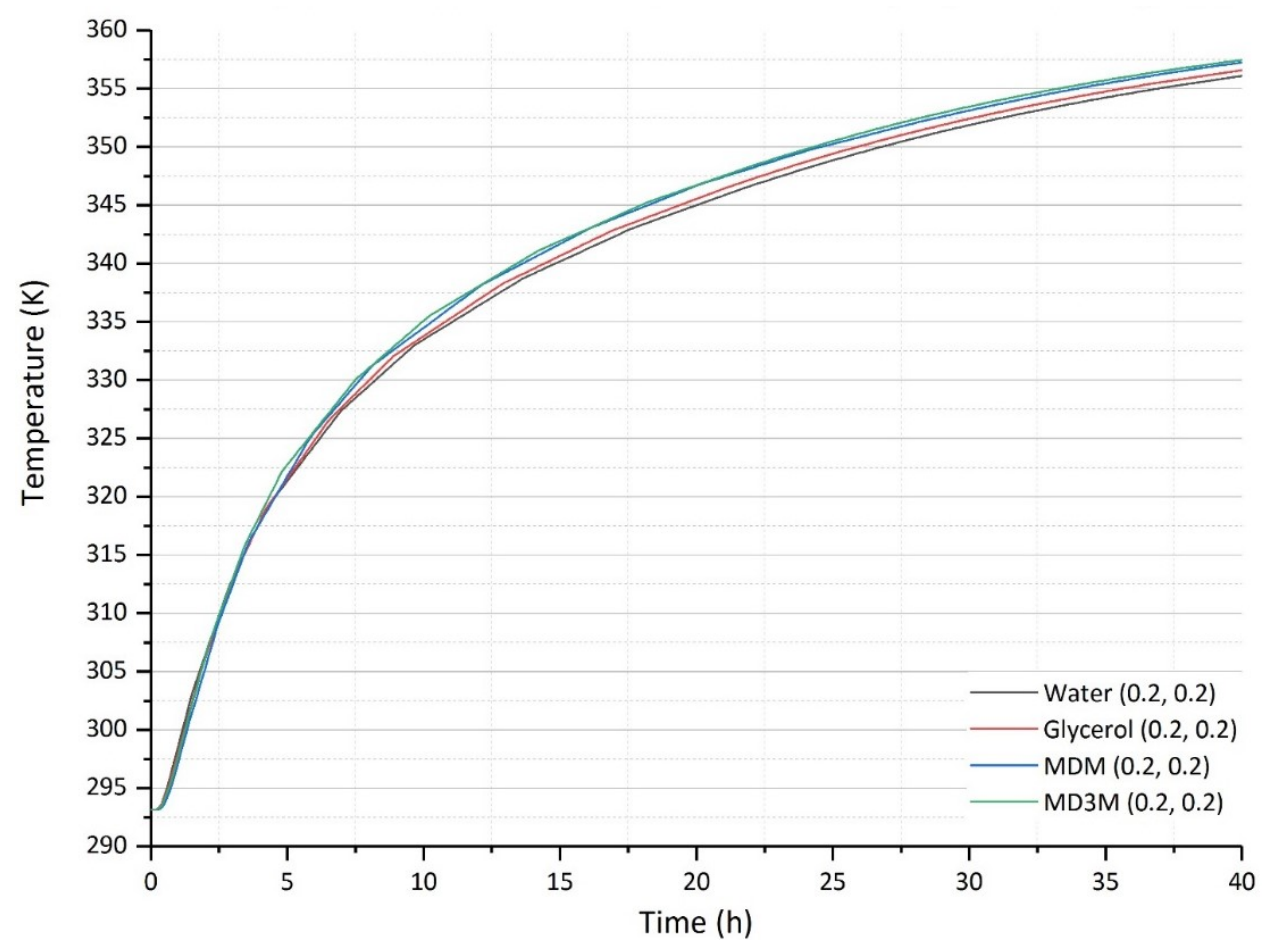

Figure 8. Temperature vs Time for all materials, top sphere, design (2)

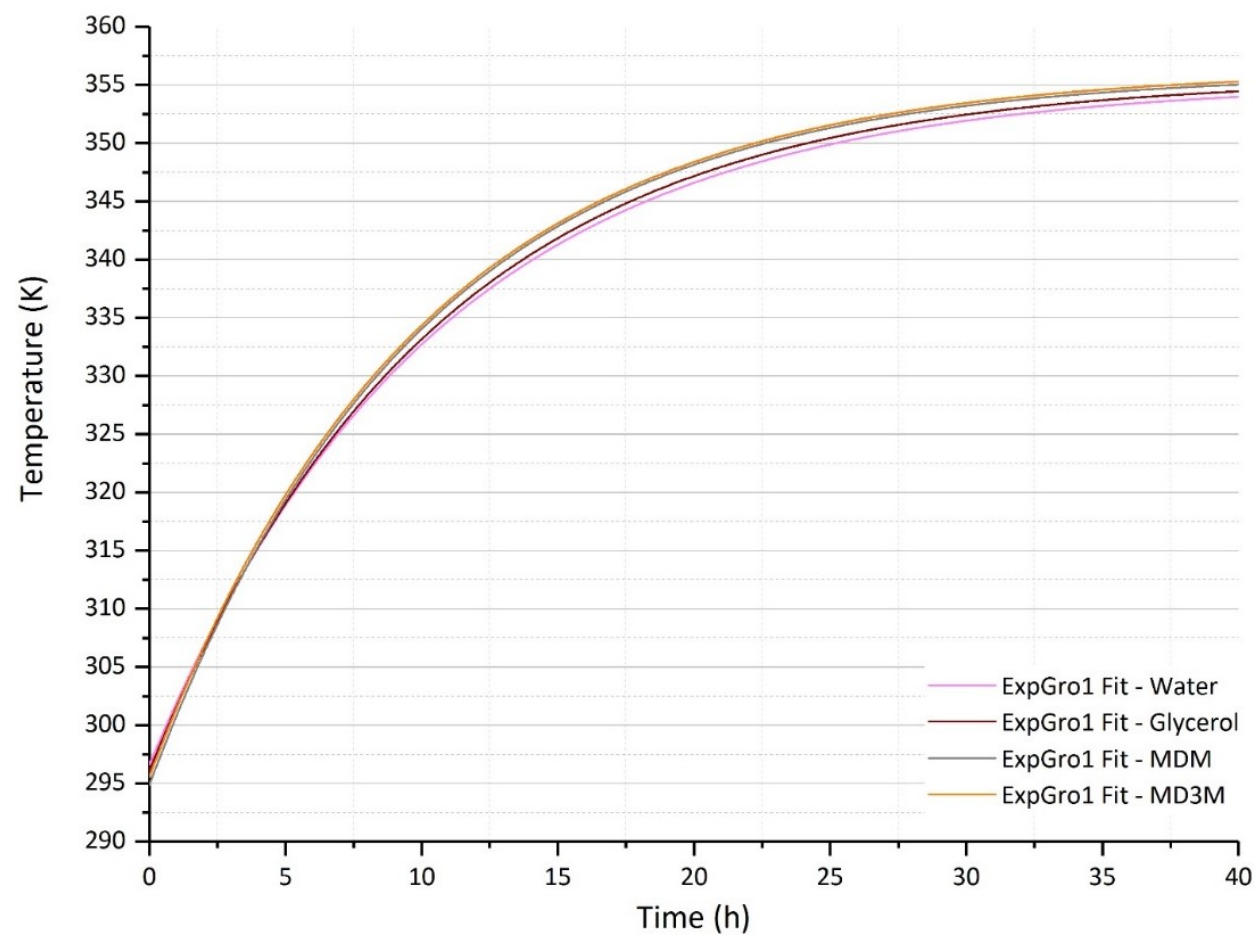

Figure 9. Temperature vs Time for all material fits, top sphere, design (2) 
Journal of Thermal Engineering, Research Article, Vol. 6, No. 3, pp. 214-226, April, 2020

Table 4. ExpGro1 fitting parameters for water (storage material), for all designs, for two positions

\begin{tabular}{|c|c|c|c|c|c|}
\hline \multicolumn{6}{|c|}{ ExpGro1 fitting: Water } \\
\hline $\mathbf{y}_{0}$ & $\mathbf{A}_{1}$ & t1 & $\mathbf{R}^{2}$ & \multicolumn{2}{|c|}{ Design Type } \\
\hline 354.94162 & -58.72181 & -9.77667 & 0.99016 & 0 Dome (1) & \multirow{4}{*}{$\stackrel{2}{\theta}$} \\
\hline 355.26706 & -58.64332 & -10.46444 & 0.99006 & 0 Dome (2) & \\
\hline 350.30246 & -56.43729 & -17.59654 & 0.99726 & 1 Dome (3) & \\
\hline 349.64796 & -55.51137 & -18.48205 & 0.99683 & 2 Domes (4) & \\
\hline 363.44477 & -72.29193 & -24.67787 & 0.99972 & 0 Dome (1) & \multirow{4}{*}{ ڤ્ } \\
\hline 362.50243 & -71.41227 & -21.46104 & 0.99967 & 0 Dome (2) & \\
\hline 365.02083 & -73.44761 & -38.27979 & 0.99980 & 1 Dome (3) & \\
\hline 364.83763 & -73.39878 & -38.30716 & 0.99976 & 2 Domes (4) & \\
\hline
\end{tabular}

Table 5. ExpGro1 fitting for all materials, for design (2), for two positions

\begin{tabular}{|c|c|c|c|c|c|}
\hline \multicolumn{6}{|c|}{ ExpGro1 fitting: All Materials, Design (2) } \\
\hline $\mathbf{y}_{0}$ & $\mathbf{A}_{1}$ & t1 & $\mathbf{R}^{2}$ & Material & Position \\
\hline 355.26706 & -58.64332 & -10.46444 & 0.99006 & Water & \multirow{4}{*}{ ô } \\
\hline 355.66233 & -59.57122 & -10.26814 & 0.99014 & Glycerol & \\
\hline 356.05674 & -61.18139 & -9.78079 & 0.99100 & MDM & \\
\hline 356.33194 & -60.74082 & -9.83866 & 0.99011 & MD3M & \\
\hline 362.50243 & -71.41227 & -21.46104 & 0.99967 & Water & \multirow{4}{*}{ है } \\
\hline 362.77706 & -71.94621 & -20.83665 & 0.99960 & Glycerol & \\
\hline 362.30548 & -72.09706 & -19.33145 & 0.99947 & MDM & \\
\hline 362.91533 & -72.49754 & -19.44217 & 0.99951 & MD3M & \\
\hline
\end{tabular}

The $y_{0}$ values for the bottom spheres are always higher than the ones for the top spheres and this applies to all materials. Equally, the time constant values for the bottom are almost much higher (double or more) than the ones for the top. The bottom graphs had almost perfect fits, whereas the top ones had more error.

For water, the highest $y_{0}$ value is the one for design (3) for the bottom position, which in turn has the lowest amplitude value. The highest amplitude value is the one at design (4) for the top position, which again corresponds to the lowest $y_{0}$ value. The time constant decreases steadily down the table, except for design (1) and (2) for the bottom spheres. The highest time value is for design (1) for the top sphere and the lowest is for design (4) for the bottom sphere. The also happens to be the case for glycerol, which follows the exact same pattern as water in terms of highest/lowest values. The arrangement is the same for both tables, even if the values differ.

For MDM, nevertheless, the highest $y_{0}$ value is given on design (4) for the bottom spheres, for which again the amplitude is its lowest value. The highest amplitude value is the one at design (4) for the top spheres, where the $y_{0}$ value is its lowest. The time constant values behave in the same manner as the previous two materials. Similar to what happens between glycerol and water, MD3M follows the exact same pattern as MDM for highest/lowest values. The arrangement is identical and the values themselves are very similar. None of these fitting parameters can be clearly attributed to any relevant material properties from Table 2 . 
Journal of Thermal Engineering, Research Article, Vol. 6, No. 3, pp. 214-226, April, 2020

\section{CONCLUSION}

A TES packed bed with liquids as sensible materials has been numerically solved using COMSOL Multiphysics. The results have been investigated and the main points can be summarized as follows:

- Changing the inlet design significantly affects the heating dynamics of the system, whereas changing the outlet changes the results marginally and can be classified as negligible.

- Materials with very different characteristics and thermal properties reach very similar final temperatures ( $3 \%$ difference).

- The temperature variation across the tank from top to bottom only also varies by approximately $3 \%$.

- Material properties appear not to have a distinct, clear relationship to the heating dynamics of the system and the maximum temperature achieved by the materials.

\section{NOMENCLATURE}

$\begin{array}{ll}c_{p} & \text { Specific heat, } \mathrm{kJ} / \mathrm{kgK} \\ m & \text { Mass, } \mathrm{kg} \\ Q & \text { Heat absorbed, } k J \\ t & \text { Time, } h \\ T & \text { Temperature, } K \\ u & \text { Inlet velocity, } \mathrm{m} / \mathrm{s} \\ V & \text { Volume, } \mathrm{m}^{3}\end{array}$

$\begin{array}{ll}\text { Greek symbols } & \\ \alpha & \text { Thermal diffusivity, } \mathrm{m}^{2} / \mathrm{s} \\ \mu & \text { Viscocity, } \mathrm{kg} / \mathrm{ms} \\ \nu & \text { Kinematic viscosity, } \mathrm{m}^{2} / \mathrm{s} \\ \rho & \text { Density, } \mathrm{kg} / \mathrm{m}^{3}\end{array}$

$\begin{array}{ll}\text { Subscripts } & \\ \text { in } & \text { Refers to final } \\ \text { sys } & \text { Refers to inlet } \\ & \text { Refers to the system }\end{array}$

\section{REFERENCES}

[1] $\mathrm{Wu} \mathrm{M}, \mathrm{Xu} \mathrm{C}, \mathrm{He}$ Y-L. Dynamic thermal performance analysis of a molten-salt packed-bed thermal energy storage system using PCM capsules. Applied Energy. 2014;121:184-95.

[2] Peng H, Dong H, Ling X. Thermal investigation of PCM-based high temperature thermal energy storage in packed bed. Energy Conversion and Management. 2014;81:420-7.

[3] Elouali A, Kousksou T, El Rhafiki T, Hamdaoui S, Mahdaoui M, Allouhi A, et al. Physical models for packed bed: Sensible heat storage systems. Journal of Energy Storage. 2019;23:69-78.

[4] Almendros-Ibáñez JA, Fernández-Torrijos M, Díaz-Heras M, Belmonte JF, Sobrino C. A review of solar thermal energy storage in beds of particles: Packed and fluidized beds. Solar Energy. 2019;192:193-237.

[5] Singh H, Saini RP, Saini JS. A review on packed bed solar energy storage systems. Renewable and Sustainable Energy Reviews. 2010;14(3):1059-69.

[6] White A, Parks G, Markides CN. Thermodynamic analysis of pumped thermal electricity storage. Applied Thermal Engineering. 2013;53(2):291-8.

[7] McTigue JD, White AJ, Markides CN. Parametric studies and optimisation of pumped thermal electricity storage. Applied Energy. 2015;137:800-11.

[8] Mertens N, Alobaid F, Frigge L, Epple B. Dynamic simulation of integrated rock-bed thermocline storage for concentrated solar power. Solar Energy. 2014;110:830-42.

[9] Lugolole R, Mawire A, Lentswe KA, Okello D, Nyeinga K. Thermal performance comparison of three sensible heat thermal energy storage systems during charging cycles. Sustainable Energy Technologies and Assessments. 2018;30:37-51.

[10] Mawire A, McPherson M, van den Heetkamp RRJ. Thermal performance of a small oil-in-glass tube thermal energy storage system during charging. Energy. 2009;34(7):838-49. 
[11] Ahmed N, Elfeky KE, Qaisrani MA, Wang QW. Numerical characterization of thermocline behaviour of combined sensible-latent heat storage tank using brick manganese rod structure impregnated with PCM capsules. Solar Energy. 2019;180:243-56.

[12] Ismail KAR, Henríquez JR. Numerical and experimental study of spherical capsules packed bed latent heat storage system. Applied Thermal Engineering. 2002;22(15):1705-16.

[13] Mawire A. Performance of Sunflower Oil as a sensible heat storage medium for domestic applications. Journal of Energy Storage. 2016;5:1-9.

[14] Lemmon EW, Bell, I.H., Huber, M.L., McLinden. M.O. NIST Standard Reference Database 23: Reference Fluid Thermodynamic and Transport Properties-REFPROP. In: National Institute of Standards and Technology SRDP, editor. 10.0 ed. Gaithersburg2018.

[15] Association GP. Physical properties of glycerine and its solutions. In: Association GP, editor. New York1963.

[16] Niyas H, Prasad L, Muthukumar P. Performance investigation of high-temperature sensible heat thermal energy storage system during charging and discharging cycles. Clean Technologies and Environmental Policy. 2015;17(2):501-13.

[17] Kylili A. TM, Ioannou I., Fokaides P.A. Numerical heat transfer analysis of Phase Change Materials (PCM) - enhanced plaster. 2016 COMSOL Conference. Munich2016.

[18] Bataineh K, Gharaibeh A. Optimal design for sensible thermal energy storage tank using natural solid materials for a parabolic trough power plant. Solar Energy. 2018;171:519-25.

[19] Whitaker S. Forced convection heat transfer correlations for flow in pipes, past flat plates, single cylinders, single spheres, and for flow in packed beds and tube bundles. AIChE Journal. 1972;18(2):361-71.

[20] Ellendt N, Lumanglas AM, Moqadam SI, Mädler L. A model for the drag and heat transfer of spheres in the laminar regime at high temperature differences. International Journal of Thermal Sciences. 2018;133:98-105. 